\title{
Elderberry Extract Outpatient Influenza Treatment for Emergency Room Patients Ages 5 and Above: a Randomized, Double-Blind, Placebo-Controlled Trial
}

\author{
Michael Macknin, $M D^{1,2}$ (D) Kathy Wolski, $M P H^{3}$, Jeffrey Negrey, $M A^{4}$, and Sharon Mace, \\ $M D^{7}$
}

${ }^{1}$ Cleveland Clinic Lerner College of Medicine, Case Western Reserve University, Cleveland, USA; ${ }^{2}$ Beachwood, USA; ${ }^{3}$ C5 Research, Cleveland Clinic, Cleveland, $\mathrm{OH}, \mathrm{USA} ;{ }^{4}$ Clinical Research Unit, Cleveland Clinic, Cleveland, $\mathrm{OH}, \mathrm{USA}$.

\begin{abstract}
BACKGROUND: Black elderberry, used medicinally for centuries, decreased influenza duration by 4 days in three previous peer-reviewed trials. US elderberry sales, possibly related to a "high severity" and "high activity" influenza season from January to March 2018, more than doubled from 2017 to 2018 to > \$100 million.

OBJECTIVE: To determine whether elderberry extract decreases influenza's duration and severity.

DESIGN: FDA-approved, investigator-initiated, Investigational New Drug, double-blind, randomized, placebocontrolled trial. Conducted January 2018-April 2019 in three emergency rooms, two suburban and one urban, in the Midwestern Health System.
\end{abstract}

PATIENTS: Eighty-seven consecutive, consenting patients, over age four, with $<48 \mathrm{~h}$ of at least 2 moderate-severity influenza symptoms and positive polymerase chain reaction influenza test.

INTERVENTION: Patients from age 5 to 12 years received placebo or $15 \mathrm{ml}$ (5.7 g) elderberry extract orally twice a day for 5 days; those > 12 years received $15 \mathrm{ml} 4$ times a day for 5 days. Patients were permitted to choose to also receive the standard dosage of oseltamivir.

MEASUREMENTS: Primary: days until all symptoms were none or mild for $21.5 \mathrm{~h}$. Secondary: days to complete symptom resolution for $24 \mathrm{~h}$.

RESULTS: The 87 participants were randomized to receive placebo $(n=44)$ or elderberry $(n=43)$. The average age was $25 \pm 20$ years, and $56 \%$ were male. The average number of days to reach all symptoms none or mild for $21.5 \mathrm{~h}$ in the placebo group was $4.9 \pm 2.8$ days compared to $5.3 \pm 3.6$ in the elderberry group ( $p=0.57$ ). The average number of days to complete resolution was $8.7 \pm 3.8$ and $8.6 \pm 3.9$ in the placebo and elderberry group, respectively $(p=0.87)$.

LIMITATIONS: Small sample size, but powered $>0.90$ to detect 2-day benefit of elderberry versus placebo.

CONCLUSIONS: We found no evidence that elderberry benefits the duration or severity of influenza. Post hoc analysis suggested primary outcomes with elderberry taken alone (without oseltamivir) were 2 days worse than with placebo taken alone. Our results contradict previous studies and demonstrate the need for further studies.

TRIAL REGISTRATION: NCT03410862

Received March 11, 2020

Accepted August 17, 2020

Published online September 14, 2020
KEY WORDS: elderberry; Sambucus nigra; influenza; treatment.

J Gen Intern Med 35(11):3271-7

DOI: $10.1007 / \mathrm{s} 11606-020-06170-w$

(c) Society of General Internal Medicine 2020

\section{INTRODUCTION}

Black elderberry (Sambucus nigra) extract has been used for medicinal purposes for centuries. ${ }^{1,2}$ In the USA, possibly related to a "high-severity" and "high-activity" influenza season from January to March 2018, ${ }^{3}$ estimated sales of elderberry herbal supplements more than doubled from 2017 to 2018 to over 100 million US dollars. ${ }^{4}$ An evidence-based systematic review by the Natural Standard Research Collaboration concluded that there is good scientific evidence that elderberry extract supplementation can effectively relieve symptoms of influenza. ${ }^{1,5-7}$

A recent review of elderberry describes its potential mechanisms of action. Elderberry has been reported "to modulate the inflammatory cytokines IL-1 and TNF-alpha in vitro, increase human basophil secretion of IL-4, IL-13, and histamine, inhibit macrophage release of proinflammatory cytokines, and contain flavonoids reported to possess antioxidant activity."1 Sambucol®, the specific elderberry extract used in our study, inhibits influenza A and B, HIV, and herpes simplex in vitro.", ${ }^{2}$ In a randomized, placebo-controlled trial, it was associated with increased hemagglutination inhibition titers to influenza B infections. ${ }^{5}$

Two previous studies, in 27 and 60 patients, found that elderberry extract supplements shortened the duration of proven influenza by approximately 4 days compared with placebo $\left(p<0.001\right.$ in both studies). ${ }^{5,} 6$. A third trial evaluated 64 patients with three or more "flu-like" symptoms. ${ }^{7}$ After $48 \mathrm{~h}$ of treatment, $28 / 32(88 \%)$ patients in the elderberry extract group had either no symptoms or one or two mild symptoms. Only 5/32 (16\%) placebo group patients showed improvement in one or two symptoms, and most symptoms remained the same or even worsened ( $p<0.001$ for all symptoms).

The standard-of-care treatment for influenza, oseltamivir, ${ }^{8}$ shortens the duration of illness by 1 day. We powered our 
study to see if elderberry extract would shorten influenza by at least 2 days.

\section{STUDY OVERSIGHT}

The investigational agent used in this study is a dietary supplement that is not approved as a drug by the Food and Drug Administration (FDA). Therefore, all requirements of the Investigational New Drug (IND) regulations had to be met in order to receive FDA approval to conduct this investigatorinitiated IND \#136452 study. This included an independent study monitoring team that oversaw all aspects of the study including, but not limited to, drug storage and dispensing, protocol adherence, accurate data entry into the data base, and regular quality assessment reviews. The institutional review board (IRB) at Cleveland Clinic approved the trial, and all patients provided written informed consent.

\section{METHODS}

\section{General Design and Selection of Participants}

This was a randomized, double-blind, placebo-controlled trial of elderberry extract supplementation versus placebo for treatment of influenza. The study was conducted at 3 emergency rooms within a large Midwestern Health System between January 2018 and April 2019. Patients were eligible if they had $\leq 48$ h of influenza symptoms, a positive rapid polymerase chain reaction influenza test, and $\geq 2 / 7$ of the following influenza symptoms graded as either moderate or severe: nasal congestion, sore throat, cough, aches and pains, fatigue, headaches, and chills or sweats. ${ }^{8}$ All eligible patients were offered the option of receiving a prescription for oseltamivir, because we were ethically concerned about denying patients access to a proven modestly effective drug if they wished to participate in our study of an unproven medication. Exclusion criteria included a known allergy to elderberry extract or oseltamivir, use of antibiotic or antiviral medication on presentation, pregnancy, cystic fibrosis, HIV, breastfeeding women, and those who did not agree to use appropriate contraception to prevent pregnancy during the study. We initially included only patients who were high risk ${ }^{9}$ for influenza-related complications in our study, because we felt high-risk patients would potentially benefit most from improved treatments for influenza. However, we decided to enroll all eligible patients as outlined above starting in February of 2018 because this facilitated recruiting adequate numbers of patients and made our findings more generalizable.

Study research personnel explained all aspects of the study, enrolled participants, and dispensed sequentially numbered identical medication bottles previously labeled by the only non-blinded study personnel, the research pharmacist, and biostatistician. The first dose of the study medication was given in the emergency room and the remaining doses were given at home using provided measuring cups.

Patients could withdraw study consent at any time. If they developed an allergic reaction to, or could not tolerate, the study medication or became pregnant, they would be asked to discontinue treatment. Patients were called daily until all symptoms were completely resolved and fever had remained less than $100{ }^{\circ} \mathrm{F}$ for $24 \mathrm{~h}$ or for a maximum of 21 days.

\section{Study Treatments}

The active treatment was a thick reddish-brown liquid. Each $15-\mathrm{ml}$ dose of the oral liquid contained the fruit juice equivalent to $5.7 \mathrm{~g}$ of Sambucus nigra (black elderberry). The placebo, except for not containing black elderberry, contained ingredients identical to those of the active medication: glucose syrup, purified water, citric acid potassium sorbate (to retard spoilage), Trusil Natural Blackcurrant Flavour, and Natural Cranberry Micron TIM. There was a single lot of study product with a shelf-life of 2 years and an expiration date of October 20, 2020. Per the manufacturer, Good Manufacturing Practice "process steps have been verified and covered through process validation done on other liquid products that are more critical and complex" including prescription medications, ensuring consistent product quality and content.

Participants aged $\geq 13$ years were instructed to orally ingest $15 \mathrm{ml}$ of the study medication 4 times a day for 5 days, and those 5-12 years old were prescribed $15 \mathrm{ml}$ twice a day for 5 days. This is the same dosage and duration of treatment used in the previous study of Sambucol® in adults ${ }^{6}$ with influenza and the same daily Sambucol® dosage given for 3 days to adults and children with influenza in another earlier study. ${ }^{5}$

\section{Study Outcomes}

Baseline data obtained included eligibility criteria, medical history, physical examination, and assessment of current influenza symptoms.

Our study's design and methods duplicated as nearly as possible all the Roche-sponsored published studies of oseltamivir versus placebo which were used to support the FDA approval of oseltamivir for influenza. As per Dobson, ${ }^{8}$

\footnotetext{
"The primary outcome was time to alleviation of all influenza symptoms. Seven influenza symptoms (nasal congestion, sore throat, cough, aches and pains, fatigue, headaches, and chills or sweats) were graded by severity as "absent" (0), "mild" (1), "moderate" (2), or "severe" (3). Alleviation was defined as when all symptoms scored as absent or mild, and remained so for at least $21.5 \mathrm{~h}(8)$."
}

The secondary endpoint was the time to complete resolution of all influenza symptoms for $24 \mathrm{~h}^{8}$ 
In addition, the following conditions and symptoms were recorded per patients' responses as "none, mild, moderate or severe" daily throughout the study: dry mouth, bad taste, nausea, vomiting, diarrhea, constipation, abdominal pain, rash, difficulty breathing, decreased drinking, and dizziness, along with the highest-recorded temperature, and an open-ended question about any other symptoms.

\section{Sample Size Determination}

Published data on Sambucol@ with the only reported standard deviations for our primary study outcome informed our sample size calculations. ${ }^{6}$ Using a 2 -sided $Z$-test for two means, 46 influenza-positive patients randomized in a 1:1 ratio would provide $90 \%$ power to detect a mean difference in duration of illness of at least 2 days with a type I error rate of 0.05 , assuming standard deviations of 1.3 and 2.5 days in the elderberry and placebo group respectively. ${ }^{6}$ We conservatively hypothesized that elderberry extract would improve the primary and secondary outcomes by approximately half the time reported in previous studies, ${ }^{5-7}$ or 2 days, versus placebo. Two days decreased duration of influenza was determined to be clinically significant, because it was double the 1-day improvement provided by the standard of care, oseltamivir. ${ }^{8}$ We assumed $30 \%$ of our emergency room patients might be lost to follow-up, so our minimal sample size was 65 . To avoid a type II error, we chose a convenience maximum round sample size number of 100 . We stopped enrollment at 87 when simultaneously all enrolled patients had completed the study, and there had been no new enrollments for 3 weeks. We therefore assumed the active influenza season had ended.

Statistical Methods.

The number of days until symptom resolution is presented using both median and interquartile range and mean and standard deviation. Categorical variables are presented as the number and percentage of patients. Continuous variables with a non-normal distribution, such as time to symptom resolution within subgroups, were tested using the two-sample Wilcoxon test. A Student's $t$ test was used for continuous variables with a normal distribution and a chi-square or Fisher's exact test for binary and categorical variables. All tests were two-tailed and performed at a significance level of 0.05 . SAS version 9.4 software (Cary, NC) was used for all analyses. Computergenerated 1:1 randomization was stratified by the biostatistician $(\mathrm{KW})$ according to age 5 to 12 years and 13 years or older.

\section{RESULTS}

\section{Participant Characteristics}

From January 2018 to April 2019, 44 patients were randomized to receive placebo and 43 patients to receive elderberry extract. Ninety-five percent (83/87) of all patients completed the entire study, and only 4 patients ( 2 per group) were lost to follow-up. (Fig. 1) The demographic and clinical characteristics at baseline are summarized (Table 1). There were no significant betweengroup differences in any of the CDC influenza high-risk criteria. ${ }^{9}$ The only baseline significant group differences were elderberry patients were more likely to have received a flu vaccine for the current season, to have chosen to take oseltamivir, and to have a lower baseline heart rate.

\section{Primary and Secondary Outcomes}

The number of days to alleviation of all influenza symptoms to none or mild for at least $21.5 \mathrm{~h}$ (primary endpoint) was not different between the treatment groups. In the patients treated with elderberry extract, time to alleviation was $5.3 \pm 3.6$ days compared to $4.9 \pm 2.8$ days in the placebo group $(p=0.57)$. The secondary endpoint, number of days to complete resolution of all symptoms, was also similar between treatment groups ( $8.6 \pm 3.9$ days for elderberry and $8.7 \pm 3.9$ for placebo, $p=0.87$ ) (Table 2). The primary and secondary resolution outcomes were also examined by whether patients had symptoms for less than or greater than $24 \mathrm{~h}$ prior to randomization, and there were no significant differences (Table 3 ).

A post hoc analysis was conducted to determine if the primary endpoint was influenced by co-administration of oseltamivir (Table 4). In those not taking oseltamivir, the elderberry group had a longer time to symptom alleviation compared to the placebo group $(7.3 \pm 3.4$ days vs. $5.1 \pm 3.4$, $p=0.02$ ), while there was no significant difference in patients taking oseltamivir concomitantly $(3.0[2.0,5.0]$ days $4.0 \pm 3.1$ vs. $4.0[2.0,6.0]$ days $4.7 \pm 3.3, p=0.35)$. There was also a significant difference between duration of illness with elderberry alone compared to elderberry plus oseltamivir ( $7.3 \pm$ 3.4 days vs. $4.0 \pm 3.1, p=0.003$ ). A similar pattern was seen when also examined by age strata (Table 4 ).

\section{Additional Outcomes}

The average time experiencing individual symptoms of any severity was not significantly different between the groups. Among individual symptoms that were moderate or severe, only the average time experiencing aches and pains was slightly longer in the elderberry group compared to placebo ( $2.6 \pm 2.2$ days vs. $1.3 \pm 0.6$ days, $p=0.02)$. (Table 2$)$.

The number of patients and the length of taking aspirin, acetaminophen, ibuprofen, cold and flu over-the-counter preparations, and antibiotics did not differ between the placebo and elderberry groups except the placebo group 41/44 (93.2\%) was more likely than the elderberry group $30 / 43(69.8 \%)$ to have taken acetaminophen $p=0.005$ (Table 5). The maximum and average body temperatures in the elderberry and placebo groups were not statistically significantly different (data not shown). The most frequently reported adverse events overall were dry mouth (5.7\%), constipation (4.6\%), rash (4.6\%), and bad taste $(3.4 \%)$. There were no significant differences in adverse events between the elderberry and placebo groups. 


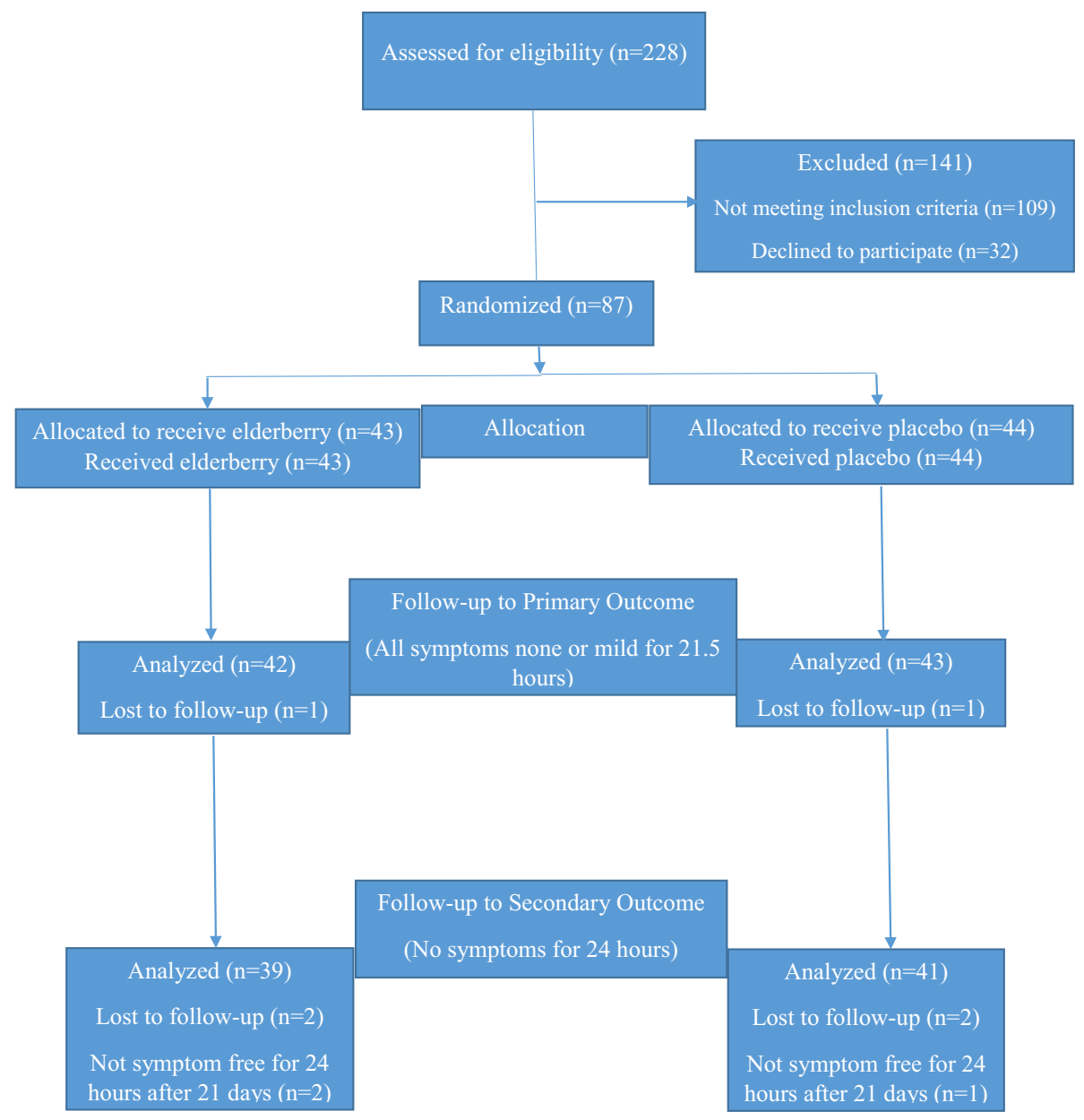

Fig. 1 Consort Flow Diagram.

At the conclusion of the study, participants were asked to guess whether they were taking placebo or active (elderberry) medication. Among placebo patients, 38/44 (86.4\%) guessed active, 5/44 (11.4\%) guessed placebo, and 1/44 (2.3\%) was unknown. Of active patients, 34/43(79\%) guessed active, 7/43 (16.3\%) guessed placebo, and 2/43 (4.7\%) were unknown.

\section{CONCLUSIONS}

We could find no literature explaining why elderberry extract might be ineffective or detrimental in treating influenza. Therefore, it is not clear why the results of this investigatorinitiated, philanthropy-supported study are so different from the positive results of the three previously reported elderberry extract treatment trials for influenza and influenza-like illnesses. Those studies were generally well-designed and clearly reported; at least two of the three were funded by the manufacturer.

The current study enrolled more patients than each of the previous three studies. Forty-six patients, our minimal targeted sample size, provided a power of 0.90 to detect a 2-day difference between placebo and elderberry treatment, approximately half the difference described in previous studies. With eighty-five patients completing our study to the primary outcome, our trial was more than adequately powered.

Another strength of our study was the inclusion of children. The only other study including patients under 18 enrolled only 25 total evaluable adults and children with influenza. ${ }^{5} \mathrm{We}$ found no significant differences in the effectiveness of elderberry extract between ages $5-12$ and $\geq 13$.

Compliance was measured by daily phone calls and returned study medications. More than $95 \%$ of patients were followed to the primary and secondary outcomes. On average, patients ages 5 to 12 took 9 of $10(90 \%)$ expected doses, and those ages 13 years and above took 17 of 20 (85\%) expected doses. We believe compliance was also a strength of this study.

One previous study used a lozenge formulation of elderberry containing $175 \mathrm{mg}$ of elderberry extract taken four times a day, ${ }^{7}$ and our study used a liquid dosage containing the fruit juice equivalent to $5.7 \mathrm{~g}$ of black elderberry taken twice a day in children under age 13 and four times a day in older patients. Although the formulation of the elderberry extract in our study was very similar to that used in two previous studies, ${ }^{5,6}$ there were minor differences. The two previous studies used a formulation with "small amounts" of honey and raspberry extract. Our study preparation used potassium sorbate (to 
Table 1 Patient Characteristics

\begin{tabular}{|c|c|c|}
\hline & $\begin{array}{l}\text { Placebo } \\
N=44\end{array}$ & $\begin{array}{l}\text { Elderberry } \\
N=43\end{array}$ \\
\hline Age of children, mean (SD), years $(n)$ & $\begin{array}{l}7.8 \pm 1.7 \\
(18)\end{array}$ & $\begin{array}{l}8.0 \pm 1.5 \\
(16)\end{array}$ \\
\hline Age of adults, mean (SD), years $(n)$ & $37 \pm 17(26)$ & $35 \pm 18(27)$ \\
\hline Males, $n(\%)$ & $22(50.0)$ & $27(62.8)$ \\
\hline \multicolumn{3}{|l|}{ Race/ethnicity } \\
\hline White, $n(\%)$ & $20(45.5)$ & $19(44.2)$ \\
\hline Black, $n(\%)$ & $16(36.4)$ & $15(34.9)$ \\
\hline Asian, $n(\%)$ & 0 & $1(2.3)$ \\
\hline Other, $n(\%)$ & $8(18.2)$ & $8(18.6)$ \\
\hline \multicolumn{3}{|l|}{ Tobacco use } \\
\hline Current, $n(\%)$ & $5(11.4)$ & $3(7.0)$ \\
\hline Past, $n(\%)$ & 7 (15.9) & $1(2.3)$ \\
\hline Never, $n(\%)$ & $32(72.7)$ & $39(90.7)$ \\
\hline Body mass index, mean (SD) & $31.0 \pm 10.8$ & $31.9 \pm 7.5$ \\
\hline $\begin{array}{l}\text { Systolic blood pressure, mean (SD), } \\
\mathrm{mmHg}\end{array}$ & $123 \pm 18.2$ & $122 \pm 17.8$ \\
\hline $\begin{array}{l}\text { Diastolic blood pressure, mean (SD), } \\
\mathrm{mmHg}\end{array}$ & $73.5 \pm 11.3$ & $71.1 \pm 9.9$ \\
\hline Pulse, mean (SD), beats per minute* & $115 \pm 19.4$ & $105 \pm 19.6$ \\
\hline Allergies, $n(\%)$ & $19(43.2)$ & $19(44.2)$ \\
\hline \multicolumn{3}{|l|}{ High-risk criteria } \\
\hline Asthma, $n(\%)$ & $15(34.1)$ & $9(20.9)$ \\
\hline Neurological condition, $n(\%)$ & $2(4.5)$ & $3(7.0)$ \\
\hline Chronic lung disease, $n(\%)$ & $3(6.8)$ & $2(4.7)$ \\
\hline Heart disease, $n(\%)$ & $4(9.1)$ & $3(7.0)$ \\
\hline Endocrine disorders, $n(\%)$ & $3(6.8)$ & $4(9.3)$ \\
\hline Received flu shot for current & $9(20.5)$ & $20(46.5)$ \\
\hline \multicolumn{3}{|l|}{ season* $n(\%)$} \\
\hline Taking oseltamivir* $n(\%)$ & $17(38.6)$ & $26(60.5)$ \\
\hline
\end{tabular}

${ }^{*} p<0.05$. Continuous variables were tested with a Student's $t$ test and categorical variables were tested with the chi-square test

retard spoilage), Trusil Natural Blackcurrant Flavour, and Natural Cranberry Micron TIM not described in the previous studies" preparations. It is uncertain if these "small" differences in formulation could have accounted for the different results in our study. A formulation of Sambucol@ minus the honey and glucose still showed inhibition of influenza virus

Table 2 Number of Days to Resolution of Symptoms

\begin{tabular}{|c|c|c|c|}
\hline & $\begin{array}{l}\text { Placebo } \\
N=44 \\
\text { Mean } \pm \text { SD }\end{array}$ & $\begin{array}{l}\text { Elderberry } \\
N=43 \\
\text { Mean } \pm \text { SD }\end{array}$ & $\begin{array}{l}\text { value* } \\
\text { valu }\end{array}$ \\
\hline $\begin{array}{l}\text { Days to resolution of } \\
\text { symptoms to mild or none for } \\
21.5 \mathrm{~h}\end{array}$ & $4.9 \pm 2.8$ & $5.3 \pm 3.6$ & 0.57 \\
\hline $\begin{array}{l}\text { Days to complete resolution } \\
\text { of all symptoms }\end{array}$ & $8.7 \pm 3.9$ & $8.6 \pm 3.9$ & 0.87 \\
\hline \multicolumn{4}{|c|}{ Average days with each symptom (for those with any symptom) } \\
\hline Nasal congestion & $4.8 \pm 3.4$ & $4.9 \pm 4.2$ & 0.89 \\
\hline Sore throat & $2.6 \pm 2.1$ & $3.5 \pm 2.8$ & 0.24 \\
\hline Cough & $6.1 \pm 4.1$ & $7.2 \pm 5.0$ & 0.27 \\
\hline Aches and pains & $2.4 \pm 1.9$ & $2.9 \pm 2.5$ & 0.35 \\
\hline Fatigue & $3.4 \pm 3.1$ & $3.3 \pm 2.8$ & 0.85 \\
\hline Headache & $2.5 \pm 2.0$ & $3.0 \pm 3.6$ & 0.52 \\
\hline Chills or sweats & $2.0 \pm 1.3$ & $2.4 \pm 1.7$ & 0.28 \\
\hline \multicolumn{4}{|c|}{$\begin{array}{l}\text { Average days with each symptom (for those with only moderate or } \\
\text { severe symptoms) }\end{array}$} \\
\hline Nasal congestion & $2.1 \pm 1.5$ & $2.5 \pm 1.9$ & 0.46 \\
\hline Sore throat & $1.8 \pm 1.5$ & $2.1 \pm 1.4$ & 0.59 \\
\hline Cough & $3.0 \pm 2.6$ & $3.9 \pm 3.3$ & 0.19 \\
\hline Aches and pains & $1.3 \pm 0.6$ & $2.6 \pm 2.2$ & 0.02 \\
\hline Fatigue & $1.9 \pm 1.2$ & $2.1 \pm 1.6$ & 0.58 \\
\hline Headache & $1.8 \pm 1.3$ & $1.8 \pm 1.3$ & 0.94 \\
\hline Chills or sweats & $1.4 \pm 0.7$ & $1.6 \pm 0.7$ & 0.52 \\
\hline
\end{tabular}

*Number of days to symptom resolution was tested with the Student's $t$ test
Table 3 Days to Resolution According to Time of Symptom Onset

\begin{tabular}{llll}
\hline \hline & $\begin{array}{l}\text { Placebo } \\
\boldsymbol{N = 2 8} \\
\text { Mean } \pm \text { SD }\end{array}$ & $\begin{array}{l}\text { Elderberry } \\
\boldsymbol{N}=\mathbf{2 6} \\
\text { Mean } \pm \text { SD }\end{array}$ & $\begin{array}{l}\boldsymbol{p} \\
\text { value* }\end{array}$ \\
\hline $\begin{array}{l}\text { Symptom onset }<24 \mathrm{~h} \\
\text { primary to randomization }\end{array}$ & $n=7$ & $n=9$ & \\
$\begin{array}{l}\text { Days to resolution of } \\
\text { symptoms (primary endpoint) }\end{array}$ & $5.1 \pm 4.2$ & $5.7 \pm 4.6$ & 0.82 \\
$\begin{array}{l}\text { Days to complete resolution } \\
\text { (secondary endpoint) }\end{array}$ & $9.0 \pm 4.9$ & $7.7 \pm 2.6$ & 0.56 \\
$\begin{array}{l}\text { Symptom onset } 24 \mathrm{~h} h \\
\text { primary to randomization } \\
\text { Days to resolution of }\end{array}$ & $n=21$ & $n=17$ & \\
$\begin{array}{l}\text { symptoms (primary endpoint) } \\
\text { Days to complete resolution } \\
\text { (secondary endpoint) }\end{array}$ & $5.1 \pm 2.4$ & $5.7 \pm 2.7$ & 0.50 \\
\hline
\end{tabular}

*Number of days to symptom resolution was tested with the Student's $t$ test

hemagglutination in vitro. ${ }^{5}$ This suggests the absence of a "small amount" of honey seems unlikely to have affected results using Sambucol®.

There were several statistically significant differences occurring by chance between the presenting characteristics in the randomly assigned elderberry and placebo groups in our trial. However, all three differences would, if anything, seem to have inadvertently biased our study to have obtained results favoring the elderberry group. The placebo group had a higher baseline pulse rate, suggesting that patients in this group were slightly more ill than those in the elderberry group. Also, by chance, more elderberry than placebo patients had received their seasonal influenza vaccination, and more elderberry patients elected to take oseltamivir. Both of these factors have been described as decreasing the severity and duration of influenza symptoms. ${ }^{8,10,11}$

Oseltamivir is a neuroaminidase inhibitor, and one of elderberry's many hypothesized anti-influenza properties is that it

Table 4 Days to Resolution of Symptoms (Primary Endpoint) by Use of Oseltamivir

\begin{tabular}{|c|c|c|c|}
\hline$\overline{N(\%)}$ & $\begin{array}{l}\text { Placebo } \\
\text { Median [Q1, } \\
\text { Q3] } \\
\text { or } \\
\text { Mean } \pm \text { SD } \\
N(\%)\end{array}$ & $\begin{array}{l}\text { Elderberry } \\
\text { Median [Q1, } \\
\text { Q3] } \\
\text { or } \\
\text { Mean } \pm \text { SD }\end{array}$ & $\begin{array}{l}p \\
\text { value* }\end{array}$ \\
\hline Not taking oseltamivir, & $\begin{array}{l}5.1 \pm 2.5 \\
26(60)\end{array}$ & $\begin{array}{l}7.3 \pm 3.4 \\
17(40)\end{array}$ & $0.02 \dagger$ \\
\hline Age $\leq 12$ years, 15 & $\begin{array}{l}5.4 \pm 2.4 \\
10(67)\end{array}$ & $\begin{array}{l}8.2 \pm 2.8 \\
5(33)\end{array}$ & $0.06 \dagger$ \\
\hline Age $\geq 13$ years, $28(65)$ & $\begin{array}{l}4.9 \pm 2.6 \\
16(57)\end{array}$ & $\begin{array}{l}6.9 \pm 3.7 \\
12(43)\end{array}$ & $0.11 \dagger$ \\
\hline $\begin{array}{l}\text { Taking oseltamivir } \\
42(49)\end{array}$ & $4.0[3.0,6.0]$ & $3.0[2.0,5.0]$ & $0.35 \dagger$ \\
\hline Age $\leq 12$ years & $4.0[2.0,6.0]$ & $2.0[2.0,3.0]$ & 0.27 \\
\hline Age $\geq 13$ years & $4.0[3.0,5.0]$ & $3.0[3.0,6.0]$ & 0.99 \\
\hline $23(55)$ & $9(39)$ & $14(61)$ & \\
\hline
\end{tabular}

*Unless otherwise indicated, days to symptom resolution was tested with a two-sample Wilcoxon rest

†Student's $t$ test 
Table 5 Concomitant Medications

\begin{tabular}{llll}
\hline \hline & $\begin{array}{l}\text { Placebo } \\
\boldsymbol{N = 4 4} \\
\boldsymbol{N}(\boldsymbol{\%})\end{array}$ & $\begin{array}{l}\text { Elderberry } \\
\boldsymbol{N = 4 3} \\
\boldsymbol{N}(\boldsymbol{\%})\end{array}$ & $\boldsymbol{p}$ value* \\
\hline Aspirin & $5(11.4)$ & $7(16.3)$ & 0.51 \\
Acetaminophen & $41(93.2)$ & $30(69.8)$ & 0.005 \\
Ibuprofen & $36(81.8)$ & $32(74.4)$ & 0.40 \\
Cold and flu preparations & $17(38.6)$ & $17(36.5)$ & 0.93 \\
Antibiotics & $3(6.8)$ & $5(11.6)$ & $0.48^{\dagger}$ \\
\hline
\end{tabular}

*Unless otherwise indicated, concomitant medications were tested with a chi-square test

FFisher's exact test

reduces hemagglutination. ${ }^{5,11}$ Therefore, these two medications that target different major influenza virulence factors might be expected to act synergistically against influenza. In fact, symptoms resolved significantly faster in the patients who received Sambucol ${ }^{\circledR}$ and Oseltamivir versus those who received Sambucol® alone. However, unexpectedly and inexplicably, symptoms took 2 days longer to resolve in patients who received Sambucol® but not oseltamivir versus those receiving placebo. There was no significant difference in time to alleviation of symptoms between the groups taking oseltamivir concomitantly. This was a post hoc analysis, so no definite conclusions can be drawn except that these findings deserve further study.

\section{LIMITATIONS}

Our study outcomes relied solely on reports of patients' symptoms. However, these are the same measures used in previous studies. Also, patients' experience of their symptoms is probably the most clinically important measure of the effectiveness of treatment. However, studies of time until viral elimination would provide an objective measure of the effectiveness of antiviral therapy.

We did not subtype the influenza viruses detected in our study and did not check for virus sensitivity to elderberry and to oseltamivir. It is possible the multiple strains of influenza presenting to our emergency rooms over 1.5 influenza seasons were unusually resistant to these medications.

We did not ask the first 33 of 87 patients enrolled in our study the exact hour of onset of their symptoms other than ensuring they were ill $<48 \mathrm{~h}$. The one previous elderberry extract treatment for influenza study that enrolled patients $<48 \mathrm{~h}$ after symptom onset, and the two studies starting treatment at $<24 \mathrm{~h}$, all showed approximately 4-day decreases in time to symptom resolution. There were also no significant outcome differences in our study between the 24 patients enrolled in the first $24 \mathrm{~h}$ after onset of their illness and the 30 enrolled 24-48 h after symptom onset. Therefore, we have no evidence suggesting that elderberry treatment initiated within the first $24 \mathrm{~h}$ of treatment might have improved the results.
Our study found no benefit of using elderberry extract for the treatment of influenza in patients ages 5 and above presenting to the emergency room within $48 \mathrm{~h}$ of onset of symptoms and suggested it might prolong time to alleviation of symptoms unless used concomitantly with oseltamivir. These results contradict the previously published studies on elderberry extract treatment of influenza. Further studies are needed, perhaps including one with patients on both oseltamivir and elderberry extract or placebo, to clearly define what, if any role, elderberry extract has as a treatment for influenza.

Corresponding Author: Michael Macknin, MD; Beachwood, USA (e-mail: macknim@ccf.org).

Authors' Contribution Michael Macknin, MD, Professor Emeritus of Pediatrics, Cleveland Clinic Lerner College of Medicine of Case Western Reserve University, author and principal investigator, was responsible for the conception, design, and interpretation of the work. Kathy Wolski, MPH, Lead Biostatistician, C5 Research, Cleveland Clinic, author, performed the biostatistics for this study. Jeffrey Negrey, MA, Research Coordinator, Clinical Research Unit, Cleveland Clinic, author. Sharon Mace, MD, Professor of Medicine, Cleveland Clinic Lerner College of Medicine of Case Western Reserve University, author. All authors were involved in the acquisition of data for the work, drafting of the work or revising it critically for important intellectual content, and final approval of the version to be published, and agree to be accountable for all aspects of the work in ensuring that questions related to the accuracy or integrity of any part of the work are appropriately investigated and resolved. The authors would like to acknowledge everyone who contributed significantly to this work. Stephanie Stoianoff, MBA, BSHA, Research Coordinator, helped with enrollment of patients, patient follow-up, and data entry. Wendy Spencer, RN, Research Coordinator Cleveland Clinic Children's, helped with enrollment of patients. Megan Villareal, BA, helped coordinate the contributions of the Clinical Research Unit study coordinators. Deborah Gladish, BA, and Karen Myers provided data management support; Craig Balog, BS, provided programming support, Gerry McConnell, BSN, RN, provided monitoring, and Tammy Gamble provided administrative support. These individuals are paid employees of C5 Research at Cleveland Clinic. John Petrich, RPh MS, Investigational Drug Service Department of Pharmacy Cleveland Clinic, received study medications and helped with blinding and proper storage and end-of-study disposal of all study medications. Amy Moore, BA, provided medical editing support from the Department of Scientific Publications at Cleveland Clinic. Lukas Kost, MD, and Aiman Altaqui, MD, of Cleveland Clinic also helped with patient enrollment. Kristen Beck, B.A., introduced the P.I., MM, to the elderberry for influenza peer-reviewed literature. Michelle Medina, $M D$, provided invaluable support as department chairman. The medical teams, including the laboratory staff, in the three participating emergency rooms provided essential support for this project.

Funding Funding was provided by the Wendel Family Foundation, the Research Program Committee of the Cleveland Clinic, and Cleveland Clinic Children's. Study medication and placebo, and no financial support, was provided by PharmaCare. PharmaCare and the other funding sources were not otherwise involved with the design of the study; the collection, analysis, and interpretation of the data; and the decision to approve publication of the finished manuscript. PharmaCare did have the opportunity to review this article prior to submission for publication as per a Materials Transfer Agreement with Cleveland Clinic.

\section{Compliance with Ethical Standards:}

Conflict of Interest: Dr. Macknin reports he has been a vegan for 10 years, and the Wendel Family Foundation is supportive of plant- 
based nutrition. Dr. Macknin also explored the possibility of pursuing a patent for a drug combining oseltamivir and elderberry extract. The Innovations Department at the Cleveland Clinic expressed the belief this combination was not patentable. Therefore, Dr. Macknin will not pursue a patent, but he encourages others to study this combination. No other authors report any conflicts of interest relative to this manuscript.

\section{REFERENCES}

1. Ulbricht $\mathbf{C}$, Basch $\mathbf{E}$, Cheung $\mathbf{L}$, Goldberg $\mathbf{H}$, Hammerness $\mathbf{P}$, Isaac $\mathbf{R}$ et al. An evidence-based systematic review of elderberry and elderflower (Sambucus nigra) by the natural standard research collaboration. J Diet Suppl. 2014;11(1):80-120.

2. Porter RS, Bode RF. A Review of the Antiviral Properties of Black Elder (Sambucus nigra L.) Products. Phytother Res. 2017;31:533-54.

3. Garten R, Blanton L, Elal AIA, Alabi N, Barnes J, Biggerstaff M, et al. Update: Influenza activity in the United States during the 2017-18 season and composition of the 2018-19 influenza vaccine. Morb Mortal Wkly Rep. 2018;67(22):634-642

4. Smith T, Eckl V, Morton C, Gillespie M, Knepper J. Herbal supplement sales in US increase 9,4\% in 2018. HerbalGram [Internet]. 2019;123:6273. Available from: www.herbalgram.org (accessed 6/24/2020)

5. Zakay-Rones Z, Varsano $\mathbf{N}$, Zlotnik M, Manor O, Regev L, Schlesinger $\mathbf{M}$, et al. Inhibition of Several Strains of Influenza Virus in Vitro and Reduction of Symptoms by an Elderberry Extract (Sambucus nigra L.) during an Outbreak of Influenza B Panama. J Altern Complement Med. 1995;1(4):361-9.

6. Zakay-Rones Z, Thom E, Wollan T, Wadstein J. Randomized study of the efficacy and safety of oral elderberry extract in the treatment of influenza A and B virus infections. J Int Med Res. 2004;32(2): 132-40.

7. Fan-Kun K. Pilot Clinical Study on a Proprietary Elderberry Extract: Efficacy in Addressing Influenza Symptoms. Online J Pharmacol Pharmacokinet. 2009;5:32-43. (No longer accessible)

8. Dobson J, Whitley RJ, Pocock S, Monto AS. Oseltamivir treatment for influenza in adults: A meta-analysis of randomised controlled trials. Lancet. 2015;385(9979):1729-37.

9. CDC.gov. People at High Risk of Developing Flu-Related Complications | Seasonal Influenza (Flu) | CDC. [Internet]. Seasonal Influenza (Flu). 2015. Available from: http://www.cdc.gov/flu/about/disease/high_risk. htm (accessed 6/24/2020)

10. Thompson MG, Pierse N, Sue Huang Q, Prasad N, Duque J, Claire Newbern E, et al. Influenza vaccine effectiveness in preventing influenzaassociated intensive care admissions and attenuating severe disease among adults in New Zealand 2012-2015. Vaccine. 2018;36(39):5916-25.

11. Jefferson T, Jones M, Doshi P, Spencer EA, Onakpoya I, Heneghan CJ. Oseltamivir for influenza in adults and children: Systematic review of clinical study reports and summary of regulatory comments. BMJ (Online). 2014;348; doi:https://doi.org/10.1136/bmj.g2545 (accessed $6 / 24 / 2020)$

Publisher's Note Springer Nature remains neutral with regard to jurisdictional claims in published maps and institutional affiliations. 